\title{
Construindo conhecimentos através do espaço sindical francês: um olhar sobre a informação e o papel do arquivo junto a uma política de memória militante.
}

Ricardo Medeiros Pimenta

\begin{abstract}
Doutorando e Mestre em Memória Social pela Universidade Federal do Estado do Rio de Janeiro (UNIRIO); com estágio doutoral na Écoles des Hautes Études en Sciences Sociales (EHESS), França. Professor tutor do curso de licenciatura em História (modalidade EAD) da Universidade Federal do Estado do Rio de Janeiro (UNIRIO). Graduado em História pela Universidade Gama Filho (UGF).
\end{abstract}

Este trabalho apresenta um recorte da tese de doutorado em andamento, acerca do papel da memória e do arquivo enquanto meios para a recuperação, instrumentalização e produção de conhecimentos. Usos que, para a produção da memória, se encontram aqui representados pelas experiências vividas pela Confederação Geral do Trabalho (CGT) e a Confederação Francesa Democrática do Trabalho (CFDT), assim como seus atores nos últimos anos. Suas atuações apontam para o desenvolvimento do diálogo presente no espaço público através do arquivo e da memória. A criação e organização de serviços de arquivo em ambas centrais, além da fundação de um Instituto de História Social no caso da CGT, evidenciam um fenômeno característico de um "desejo de memória" por parte dessas instituições. Nosso objetivo é, portanto analisar e nos debruçar sobre os motivos e o interesse acerca do constante e crescente uso da memória e do desenvolvimento dos arquivos sindicais.

Palavras-chave: Memória; Sindicato; Arquivo; Identidade; Política. 


\title{
Building knowledges through french's trade union space: one look into information and the archive's role with a militant politic of memory.
}

\begin{abstract}
This paper presents a small extract from PhD's thesis in progress concerning the paper of memory and archives as a way to retrieval, instrumentalization and knowledge's production. The uses of memories' production are here represented by lived experiences from General Confederation of Work (CGT) and Democratic French Confederation of Work (CFDT), as well as theirs social actors in the past few years. Its performances point out to the actual debate's development in the public space about memory and archives' roles. The creation and organization of archive's services in both confederations' offices, beyond the foundation of an Institute of Social History (at CGT's case), evidences a characteristic phenomenon of a "memory desire" as part of these institutions. Our goal is to investigate and analyze the reasons and the interests concerning the everlasting use of memory and union's archives development.
\end{abstract}

Keywords: Memory; Union; Archive; Identity; Politic.

\section{Introdução}

Nas últimas décadas um crescente interesse sobre a memória, sobretudo pautado em uma política de arquivos cada vez mais ampla, passou a fazer parte do cenário francês e de suas diversas instituições, associações e outros meios de representação de grupos sociais.

O crescente acesso à informação, aos meios de comunicação cada vez mais velozes e diversos, vem mostrando que os sindicatos, partidos e demais grupos ligados às classes populares - dando destaque à classe trabalhadora - passaram a encarar nas últimas décadas uma nova gama de desafios ligados à identidade, legitimidade, conhecimento e informação. Estes eixos foram fortemente abalados no cenário mundial pela atomização, bem como por uma relativização intensa, do domínio das práticas sociais e de seus discursos - insuflados por um suposto fim de ideologias como o socialismo, comunismo, entre outras - deixando as grandes metanarrativas, erigidas pelas disciplinas sócio-históricas, no terreno da "incredulidade" (Cf. LYOTARD, 1979: 7).

As instituições sindicais e suas confederações atravessaram, portanto, este período sendo marcadas historicamente pelos momentos de 
crise, de evasão de seus participantes e de enfraquecimento político junto à sociedade civil e às demandas direcionadas ao Estado. Tais mudanças podem ser exemplificadas por fenômenos como reestruturação produtiva, terceirização, baixa da população industrial (NOIRIEL; 2002, pp. 238-239) e do número de sindicalizados (ROSANVALLON, 1998, p. 48), além do crescente fechamento de fábricas e das mudanças espaciais, econômicas e sociais características desse momento. Velhas estruturas e saberes se tornaram ameaçadas pelo desaparecimento. Assim, é correto afirmar que em meio às mudanças das relações de trabalho e das políticas econômicas na França na transição dos anos 1970 aos 1980, não apenas os sindicatos se enfraqueciam como também sua imagem era fortemente abalada.

Entretanto, foi naquele período onde o mundo do trabalho marcava em sua história as duras transformações e suas conseqüências por vezes nefastas que o cenário francês também suscitaria outros debates, sobretudo nos métodos de reorganização e reestruturação das instituições sindicais e de suas respectivas confederações, visando não apenas uma modernização das suas estruturas como de suas atuações orgânicas e públicas.

\section{Política de arquivos no cenário nacional: o papel dos sindicatos}

A partir do final da década de setenta buscas e discussões sobre o que seria a identidade nacional francesa eram trazidas à superfície dos debates no campo intelectual - tanto de esquerda como de direita - e no campo do debate público que se alimentava dos novos meios de comunicação e informação (NOIRIEL, 2007: 76). Este campo fértil de questões e problemas buscava compreender socialmente a identidade nacional francesa que passava a figurar o vocabulário político do Estado francês ao longo da década seguinte após se pôr em xeque a partir do maio de 68.

Ainda no campo intelectual, já ao final dos anos setenta era notória a crescente importância dada aos arquivos privados pela historiografia econômica e social francesa que distinguia seu forte valor para a história da França, reconhecendo sua natureza de patrimônio nacional.

"O interesse crescente pelos arquivos privados corresponde a uma mudança de rumo fundamental na história das práticas historiográficas. Dois fatores, ligados aliás um ao outro, me parecem ser capazes de esclarecer o gosto pelo arquivo privado. O primeiro é o impulso experimentado pela história cultural e, mais particularmente, a multiplicação dos trabalhos sobre os intelectuais. O segundo está vinculado à mudança da escala de observação do social, que levou, sobretudo pela via da micro-história e da antropologia histórica, a um interesse por fontes menos seriais e mais qualitativas". (PROCHASSON, 1998: 7). 
Era naquele momento que em 1979 se criava nacionalmente a Lei de Arquivos; insuflada pelo desenrolar de questões ligadas à identidade nacional e ao patrimônio industrial; pelo crescimento da influência da business history americana na historiografia francesa; e pela sabida contribuição que os arquivos de propriedade privada poderiam oferecer às análises ligadas à história social, cultural, política e econômica.

De fato, a idealização de um Centro de Arquivos do Mundo do Trabalho em 1983, em Roubaix (MAUROY; 2002, p. 37), apontava para um Estado cada vez mais sensível às necessidades de uma política direcionada aos arquivos nacionais e, sobretudo, à necessidade de se evitar o desmembramento de centenas de fundos de coleções e demais materiais que, à sombra do desfalecimento das instituições sindicais viviam a real ameaça de serem destruídos. O Estado assumia o controle e proteção, quando necessário, do que se julgava de interesse para o patrimônio histórico francês.

Esses acontecimentos têm como um dos marcos fundamentais a criação do Centro de Arquivos do Mundo do Trabalho - subordinado ao Arquivo Nacional da França - em uma antiga fábrica de algodão na cidade de Roubaix, localizada no extremo norte do país. Ali seria criado instrumento estatal para receber e centralizar os arquivos de diversos organismos, grupos ou pessoas físicas que não possuíam a possibilidade de mantê-los. Coroava-se naquele ato a mudança na orientação política da importância e utilidade dos arquivos franceses - fossem eles públicos ou privados - juntamente com um momento particular de mudanças profundas tanto na esfera governamental como no plano econômico.

Havia, portanto, uma tomada de consciência, em nível estatal, de que se tornava necessária a organização, proteção e legitimação de arquivos; sobretudo, os ligados à classe trabalhadora francesa. No entanto restava saber os motivos pelos quais, em meio a um cenário de crise da estrutura sindical francesa, surgiam naquele momento os projetos e políticas de arquivo na Confederação Geral do Trabalho $^{1}$ (CGT) e na Confederação Francesa Democrática do Trabalho² (CFDT). Não há dúvida que 0 interesse pelos arquivos privados, principalmente ligados às trajetórias militantes, possuía um claro valor para a historiografia contemporânea; no entanto a apropriação do discurso pelas próprias instituições sindicais apontava para alguns fatos de grande importância.

No contexto pragmático, é clara a intenção de controle da informação que circularia no espaço público. O arquivo sindical, militante, confédéral, não mais seria apenas um lugar de depósito, morto. Para tal se tornava necessário geri-lo. Programar estratégias, práticas e ferramentas as quais pudessem assegurar a reprodução das informações, salvaguardando-as, da maneira adequada à imagem pública daquela instituição. Estes arquivos sindicais passariam atuar não apenas como guardiões, mas sim como órgãos "comunicadores da informação" (BLAI, ENNS, 1989-1990: 56) nos espaços de atuação daquelas instituições.

\footnotetext{
${ }^{1}$ Confédération Générale du Travail - CGT.

${ }^{2}$ Confédération Française Démocratique du Travail - CFDT.
} 
Iniciava-se o controle do que seria produzido e distribuído através dos meios de comunicação os quais também passavam por uma intensa evolução de suas tecnologias e capacidades.

No contexto da produção do conhecimento, podemos afirmar que a ida aos arquivos pelas confederações como a CGT, por exemplo, atendia ao impulso daquela organização em não mais ficar à margem da construção historiográfica sobre a classe operária francesa, sobre a esquerda e seus militantes, sobre o comunismo ou tantos outros temas e objetos dos quais ela fazia parte. Ou seja, era necessário construir seu próprio conhecimento a partir de seus próprios mecanismos políticos, informacionais e intelectuais. Além disso, tanto a CGT como a CFDT possuíam uma intenção em legitimar-se no espaço público e político através da trajetória histórica e militante.

Lembremos que a experiência, sua garantia de transmissão, reside entre outras questões na possibilidade de sedimentação intersubjetiva que permeia os indivíduos e grupos sociais (BERGER \& LUCKMANN, 2008: 96); ou seja, na memória. No entanto, o arquivo permite que a este fenômeno seja instaurado um suporte que, previamente selecionado, institucionalizado, controlado e mantido, possa atuar como base de referência à acumulação daquilo que convencionamos chamar de informação.

Entre as ligações do arquivo; seu potencial de informação; o processo da pesquisa histórica e seus usos nas esferas públicas e privadas se inseriam ali a produção do conhecimento através de seus usuários, tendo em vista o que passava a ser memória e o que ainda se encontrava na courte durée da idade administrativa (CERUTTI; FAYET; PORRET; 2006: 12-13).

Assim, a experiência francesa em relação aos sindicatos, à classe trabalhadora e suas relações com o passado se tornou um bom campo para colocar em foco as questões referentes ao uso e ao objetivo das atividades relacionadas à memória realizadas nos espaços sindicais. Da mesma forma, alargando o leque de questionamentos postos acerca dos usos e "abusos" da memória por parte dos grupos sociais e suas instituições.

Entre eles, o primeiro fator de interesse foi perceber que a memória e o papel do arquivo no espaço sindical francês tomavam forma e prioridade coincidentemente a partir do final dos anos setenta - um momento de crise em relação ao sindicalismo francês. Ali, a valorização do arquivo tomava seu corpo ao passo que as incertezas quanto ao futuro tornavam-se mais espessas e indecifráveis. O segundo mostrava que tais atividades acompanhavam um processo de modernização e desenvolvimento de novas estratégias sindicais - algo que anos mais tarde seria presente na experiência brasileira através de alguns sindicatos ligados à corrente militante do novo sindicalismo - onde a idéia de uma política de memória e de preservação de arquivos sindicais e militantes se vinculava a um discurso de busca pela salvaguarda da identidade da classe trabalhadora e de sua memória coletiva; convergindo para um 
processo institucionalizante do que seria a memória daquele sindicato, associação ou confederação.

\section{As confederações do trabalho francesas e o dever de memória}

Em 1980, através de uma proposta de projeto, o militante e escritor Marc Piolot (implicado profundamente com a CGT francesa e suas atividades) apontava no âmbito daquela confederação, em consonância com as questões debatidas em âmbito nacional, o urgente problema da falta de uma política de arquivos efetiva na instituição.

Entre muitos tipos de documentos produzidos diariamente pela prática militante e institucional da CGT, a destruição de grande parte deles - muitos inclusive de valor histórico inegável - era corrente. Documentos, resoluções, cartas, atas, entrevistas em áudio e vídeo, por exemplo. Dados e mais dados, documentos e registros eram eliminados pelo amadorismo de um movimento e de uma instituição desprovida dos mesmos. Piolot justificava, nesse sentido, a necessidade de se preservar os mesmos de maneira útil para a própria confederação, compreendendo que a informação ali fazia parte da possibilidade da construção do conhecimento no locus militante da CGT.

"Este problema (...) torna-se mais urgente para resolver (...) numerosos documentos são produzidos (...). Todas essas riquezas deveriam ser conservadas e organizadas. Infelizmente, este não é o caso das nossas organizações aonde a crescente negligência conduz quase sempre às destruições sistemáticas ou acidentais de documentos dignos de arquivos. (...) Estas carências são extremamente prejudiciais à nossa organização. Em primeiro lugar, porque é a sua memória que nós destruímos, mas também porque acaba por se tornar muito difícil (e, em certos casos, impossível) o conhecimento rigoroso do passado que, por conseguinte, a CGT não obtém plenamente se apoiando sempre, entre outras coisas, sobre falsificações ou manipulações históricas. (...) os documentos de hoje, que são a história de amanhã não são conservados sistematicamente, posicionados e classificados". ${ }^{3}$

A intenção de Piolot demonstrava a necessidade urgente em buscar meios para que a própria produção militante não fosse a posteriori destruída por eles mesmos. Outro fator de fundamental importância para se compreender tal urgência é a mudança de endereço da sede da CGT, localizada até então na Rua La Fayette no centro de Paris para o banlieue de Paris em Montreuil. O esvaziamento da histórica sede do centro de Paris fez com que antigos documentos guardados nos porões da CGT

\footnotetext{
INSTITUT CGT D'HISTOIRE SOCIALE. Arquivo: Françoise Bosman. PIOLOT, Marc. «Projet d'un règlement du problème des archives de la CGT ». 27 de fevereiro, 1980.
} 
necessitassem de um novo local de guarda. Não obstante, na nova sede, se ergueria um moderno departamento pronto à administrar e operar os arquivos da CGT em parceria com as novas tecnologias disponíveis.

Este momento tornou-se propício para encampar a busca por um diálogo com os meios acadêmicos visando erigir no espaço simbólico e social da CGT um pólo de pesquisa sobre sua história, garantindo assim a legitimidade não apenas do futuro Instituto de História Social, como igualmente da instituição que o circunscrevia, a própria CGT. Assim, pensar a questão acerca da organização dos arquivos da CGT é também um exercício de reflexão sobre a possibilidade de utilização dos mesmos contra um cenário mais e mais "árido" no tocante às práticas combativas militantes, sindicais. Ela atende ao conjunto de obstáculos e fenômenos que puseram a esquerda francesa em uma situação delicada durante os anos 1980.

A utilização dos arquivos sindicais como meio de produção de materiais, que engendram a imagem sindical por vezes idealizada e por vezes esquecida, aponta para o que consideramos como os "usos políticos do passado", cujas instituições aqui mencionadas, e seus atores, buscam realizar de acordo com Hartog e Revel o que diríamos ser um impulso próprio das instituições em mobilizar todos os recursos possíveis como simbólicos, narrativos, cognitivos, escritos, materiais e imateriais que possam caracterizar o uso político presente em todo o discurso histórico (HARTOG; REVEL; 2001: 13-14).

Esse poder é assegurado pela preservação de uma identidade coletiva - nesse caso criada por meio de uma "bricolagem" institucional - que estará presente no discurso em comum ligado à orientação política da instituição sindical em questão. Neste caso, a criação dos arquivos da CFDT e sua política de preservação da memória de sindicatos e de suas atividades; a fundação do Instituto de História Social (IHS) da CGT juntamente com a criação da revista Cahiers de Histoire Social de I'IHS; além de diversos outros acontecimentos paralelos, evidenciavam que a política orgânica de arquivos em desenvolvimento no início dos anos oitenta percorria um caminho importante no contexto histórico atual: o de "dar sentido à evolução política das instituições" (CERUTTI; FAYET; PORRET; 2006: 14), notadamente aqui exemplificadas pela CGT e CFDT.

Formava-se dessa maneira o substrato para a manutenção de uma memória de face social e, sobretudo política. Lembremos que independente da situação coletiva ou individual, uma questão é certa: "a lembrança do passado é necessária para afirmar sua identidade" (TODOROV; 2000, p. 180). Com um espaço para consulta de seus arquivos, uma biblioteca de títulos referentes ao mundo do trabalho, boletins periódicos desde o ano de 1982 intitulados: Les Cahiers de I'Institut CGT d'Histoire Sociale, iconografias e sítios na internet, o IHS está em constante movimento, adaptando-se às novas tecnologias e meios de veiculação e controle da informação acerca da CGT e da produção de seu conhecimento. Permitindo que parte da memória militante sindical francesa não se "esvazie" no tempo administrando-a 
através de ferramentas características do campo da tecnologia da informação (TI); possibilitando igualmente que os militantes também sejam agentes ativos do conhecimento ao poderem consultar os registros, documentos e demais fontes; além de permitir que o acesso ao material em questão esteja aberto também ao público em geral.

O IHS promove estudos, cursos e debates no espaço orgânico dos sindicatos e da confederação, nos espaços acadêmicos, e no grande espaço público da sociedade civil. Atua fortemente, ainda, em outras frentes que dizem respeito à formação sindical e às datas comemorativas que são sempre motivo de atuação da CGT, como é o caso das experiências vividas pela sociedade francesa no Maio de 1968, mas, sobretudo em relação às atividades acerca do papel do arquivo na vida militante. Este é o caso, por exemplo, da criação de um curso de formação oferecido a sindicalistas que desejassem trabalhar com arquivos, viabilizado pelo IHS para outras instituições sindicais na França, já no ano de $1985 .^{4}$

O caso da CFDT não é menos importante dentro desse contexto de valorização dos documentos e demais políticas relacionadas ao papel do arquivo no mundo sindical. Seu serviço de arquivo é igualmente aberto ao público em geral e possui diversos fundos referentes a diversos sindicatos e representações de trabalhadores franceses e também outros internacionais. Sua atuação é vizinha ao setor de comunicação e propaganda da CFDT, gerando em suas atuações conjuntas um conhecimento acerca de sua organização e atividades de grande disseminação graças às mídias impressas, eletrônicas e imagéticas. Um grande exemplo se faz presente através da webpage da CFDT, na qual é possível visualizar informações de atividades sindicais, movimentos, e prestação de serviços; além de parte da história da confederação através de vídeos online.

A atuação da CFDT e sua relação com a memória é inegável, pois a própria memória lhe dá a legitimidade e identidade, uma vez que sua origem se mistura à Confederação Francesa de Trabalhadores Cristãos (CFTC). ${ }^{5}$

Por sua vez, os arquivos da CFDT desempenham um importante papel para alguns grupos de trabalhadores e sindicatos. Este foi e é o caso dos trabalhadores da indústria automobilística da Renault de BoulogneBillancourt, localizado na região periférica sudoeste de Paris. Este caso deveu-se primariamente ao fechamento da fábrica e ao decrescente poder do sindicato que os representava. Os arquivos dos trabalhadores, suas fontes, não possuíam lugar físico para serem guardados e paralelamente ao esforço de uma associação de antigos trabalhadores da Renault Bolougne-Billancourt, a CFDT atuou fortemente para salvaguardar e

\footnotetext{
${ }^{4}$ Fichas de inscrição de militantes e sindicalistas inscritos para cursar o estágio de "estudos sobre arquivos" realizado pelo IHS da CGT de Paris em 1985. CCA, caixa arquivos confederais 1983 1999. Instituto de História Social da CGT. Arquivos confederais. 2008.

${ }^{5}$ Confédération Française des Travailleurs Chrétiens - CFTC.
} 
organizar o acervo que ao "tirar da poeira" ${ }^{6}$, passava a inserir no discurso histórico daquela instituição um conjunto de dados e informações legitimadoras a sua própria vida institucional.

Estes motivos podem validar, portanto, a hipótese de que a criação e organização de serviços de arquivo em centrais como CFDT e CGT, além da fundação do Instituto de História Social no caso da CGT no ano de 1982, constituem um fenômeno característico desse, então, "desejo de memória".

As apropriações sociais das informações referentes à própria historicidade da classe trabalhadora sugerem que a produção de conhecimentos viabiliza um discurso memorial característico dos grupos sociais e suas respectivas instituições, mesmo que eles ainda tentem mostrar imparcialidade.

"Os Institutos de História Social são uma criação relativamente recente (...) Eu penso que efetivamente isso corresponde, sua criação, o desenvolvimento de seus institutos, porque eles se desenvolvem no momento (...) O objetivo [do estatuto do IHS] é de fazer com que a história justamente, a história não seja mais... Como dizemos? Instrumentalizada. Possibilitar que o olhar histórico possa evadir-se das questões imediatas que se colocam ao interior do sindicato da CGT em particular". (DECISIER; 2008). ${ }^{7}$

Ainda assim, é necessário saber que essas produções são úteis à imagem política do sindicato, das confederações e do poder político neles existente. São os "usos políticos do passado" e sua instrumentalização, logicamente, que viabilizam essas práticas de controle da memória, então, coletivizadas pelas instituições que acabam por escolher qual será a informação, o conhecimento a ser guardado e qual será a experiência de passado que atenderá aos seus interesses comuns conforme o conceito de "justa memória" formulado por Paul Ricoeur (2000).

Logo que nós criamos, há vinte anos, o Instituto CGT de História Social, não estava evidente para todo mundo que este novo instrumento de nossa atividade sindical respondia a uma necessidade. Sua utilidade se averiguou progressivamente, à medida que nossas iniciativas diversificadas mostravam qual ponto podia contribuir para a propagação da CGT, ocupando um terreno até então reservado estritamente aos historiadores. Uma experiência, no seio de um sindicalismo

\footnotetext{
${ }^{6}$ Carta de Michel Glandus (agente da CFDT) a Jacques Brohand, responsável pela organização dos arquivos de Boulogne-Billancourt em 1993.. Arquivos confederais da CFDT. Pasta Renault Boulogne-Billancourt. 2008.

7 DECISIER, Donat. Entrevista concedida a Ricardo Medeiros Pimenta. Paris, 23 jun. 2008. O entrevistado ocupa o cargo de Secretário Geral; responsável pelo IHS da CGT.
} 
pouco inclinado - não como suas origens - a refletir sobre a história". (SEGUY; 2002).

Os anos posteriores à criação do IHS foram de extrema produtividade no tocante ao esforço em transmitir a todos os militantes a importância e necessidade de uma tomada de consciência sobre o valor dos documentos e fontes produzidos na militância. A atuação do IHS buscou mostrar esse valor; sobretudo, devido ao fato de que sua criação constituía essa "peça motriz" para uma fala protagonizada pelo lado dos sindicatos, podendo assim se expressar no contexto da produção historicista.

Mesmo suscetível às instrumentalizações da memória e do conhecimento histórico no âmbito do IHS, suas atividades abriram possibilitaram a construção de uma via de comunicação entre as vozes de militantes e demais atores sociais ligados na durée por experiências passadas que estiveram por vezes esquecidas no espaço público.

Uma vez que os próprios trabalhadores e, nesse caso, suas instituições representativas de classe se inserem na manutenção e produção de informações as quais serão fundamento para seu próprio discurso histórico, sócio-político e econômico, novas redes de troca de experiências surgem no espaço dos arquivos privados e de sua gerência.

A experiência da CFDT e principalmente, a da CGT configuram esse "trabalho" e "dever" de memória, característico em ambas as instituições e que eclodem justamente no início dos anos oitenta. "A informação está no coração da ação sindical. Nós afirmamos (...) que não há ação sem informação". ${ }^{8}$

\section{Conclusão}

A abertura de canais de discussão e de produção intelectual junto ao arquivo sindical e seus órgãos e associações, direcionados não apenas para os militantes, mas para uma sociedade mais ampla e plural, indicam, portanto, uma possível retomada de consciência de classe através do reconhecimento de seu papel histórico e da possibilidade de criação de uma política de arquivos fundamental para essas instituições. A utilização do arquivo como meio de produção de materiais que engendram uma imagem sindical por vezes idealizada e por vezes esquecida caracterizam os usos políticos do passado que essas instituições e seus atores buscam, portanto, realizar.

O acesso à informação e a possibilidade de contribuição para a formação de um conhecimento acerca do passado - engendrado a partir das instituições e de seus atores - é, hoje, cada vez mais presente nas

\footnotetext{
${ }^{8}$ Extraído de "La CFDT et I'information" In: XXXVI Congrès Confédéral de Nantes. 1973. Arquivos confederais da CFDT. Paris.
} 
redes sociais que compõem o cenário mundial do trabalho. Este trabalho buscou contribuir para a identificação desse fenômeno, tendo em conta as particularidades e similitudes existentes no mundo sindical. Sendo assim, vale dizer que o processo existente de valorização da memória por meio de estratégias que buscam uma reconfiguração dos objetivos e atividades do arquivo no espaço sindical, além de suas diferentes mediações e apropriações, não deixa de ser um fenômeno transnacional que merece ser compreendido mais cautelosamente.

Os trabalhos de memória realizados em alguns espaços sindicais contemporâneos auxiliam diretamente as práticas de formação sindical, de publicidade, comemorações e de manifestações em diferentes espaços sociais e localidades. Seu emprego, portanto, busca atuar na sociedade civil de maneira a preservar uma memória e a permitir a entrada desses setores nos quais ela se forma, no debate histórico.

Revistas, atividades comemorativas, produções bibliográficas, além de meios virtuais e demais vetores que se fundamentam nas atividades do arquivo do Instituto de História Social da CGT e dos arquivos confederais e interfederais da CFDT mostram que essas confederações possuem não apenas uma política de arquivo, como também uma intenção em construir e resguardar a imagem e a memória da experiência de lutas vividas no âmbito de ambas as instituições. O rápido acesso às informações, ao conteúdo de parte relevante desses acervos através da internet não apenas possibilita um amplo acesso independente do parâmetro quantitativo àquela que se torna a memória representante do grupo ao qual o sindicato em questão está ligado, como permite que esse conhecimento não circule unicamente nos espaços de atuação sindical, fabril, ou familiar de seus usuários.

A informação está, portanto, em um espaço aberto à sociedade civil. E essa questão, no entanto, requer também cuidado. Os debates são indispensáveis, pois sabemos que parte da natureza da memória é ser um produto gerado no conflito. Seja individual, política, institucional, de grupos ou religiosa a memória é construída e "enquadrada" como sendo a memória do grupo e, por essa razão, jamais estará livre de discordâncias, pois ela é produto de quem lembra e uma ação para o futuro.

O arquivo e seus diversos empregos, seu desenvolvimento e defesa denunciam essa problemática em torno da preservação da memória. No caso das confederações sindicais aqui estudadas ele é marca do início de uma visão política cuja preservação documental se torna fundamental para a compreensão por parte dos militantes e demais atores da sociedade civil da história e memória das categorias operárias representadas nas atividades sindicais.

Conhecer, portanto, os motivos pelos quais essas atividades têm início, mais fortemente a partir dos anos oitenta, é procurar compreender o papel e intenções de seus atores à época cujas atividades no desenrolar dos últimos anos vêm mostrando à sociedade civil não apenas outra história, mas também uma memória pertencente aos militantes e sindicalistas do passado. 


\section{Referências}

BACHELARD, Gaston. A dialética da duração. São Paulo: Ática, 1994.

BERGER, Peter L; LUCKMANN, Thomas. A construção social da realidade: tratado da sociologia do conhecimento. 29a Ed. Petrópolis, Vozes: 2008.

BLAIS, Gabrielle; ENNS, David. "Intensificando o 'nobre sonho: programação política nos arquivos canadenses". In: ACERVO - Revista do Arquivo Nacional, Rio de Janeiro, p. 55-68, v. 4, n. 2, jul./dez. 1989 - v. 5, n.1, jan./jun. 1990.

CERUTTI, Mauro, FAYET, Jean-François, PORRET, Michel (édit.). Penser l'archive. Lausanne: Éditions Antipodes (coll. "Histoire"), 2006.

DECISIER, Donat. Entrevista concedida a Ricardo Medeiros Pimenta. Paris, 23 jun. 2008.

HALBWACHS, Maurice. La mémoire collective. Paris: PUF, 1950.

HALBWACHS, Maurice. Les cadres sociaux de la mémoire. Paris : Albin Michel, 2004.

HARTOG, François. REVEL, Jacques. Les usages politiques du passé. Paris: EHESS, 2001.

HONNETH, Axel. The Struggle for Recognition: The Moral Grammar of Social Conflicts. Cambridge/Massachusetts: The MIT Press, 1996.

HUYSSEN, Andreas. Seduzidos pela Memória: arquitetura, monumentos, mídia. Rio de Janeiro: Aeroplano, 2000.

LYOTARD, Jean-François. (1979). La condition postmoderne: rapport sur le savoir. Paris: Minuit.

MAUROY, Pierre. «Les archives du monde du travail ». In: ELGEY, Georgette. Les Français et leurs archives: actes du colloque au Conseil économique et social, 5 novembre 2001. - Paris: Fayard, 2002.

NOIRIEL, Gérard. Les Ouvriers dans la société française, XIXe-XXe siècle. Éditions du Seuil, 2002.

NORA, Pierre. Entre memória e história: a problemática dos lugares; Revista do Programa de Estudos Pós-Graduados em História e do Departamento de História. 10. São Paulo. (1993): 7-27.

RICOEUR, Paul. La Mémoire, I'histoire, l'oubli. Paris, 2000.

RICOEUR, Paul. Parcours de la reconnaissance. France: Folio, 2005.

SÉGUY, Georges. «20 ans après ». In: Les cahiers de l'institut CGT d'histoire sociale. N.81, mars 2002.

ROSANVALLON, Pierre. La question Syndicale, Paris: Hachette, 1999. 
francês: um olhar sobre a informação e o papel do arquivo

junto a uma política de memória militante

TODOROV, Tzvetan. Mémoire du mal, tentation du bien: ênquete sur le siécle. Robert Laffont, 2000. 